\title{
Acesso e permanência das mulheres com deficiência no ensino superior: Refletindo
}

\section{sob a ótica da inclusão}

\author{
Access and permanence of women with disabilities in higher education: Reflecting from the \\ perspective of inclusion \\ Acceso y permanencia de las mujeres con discapacidad en la enseñanza superior: Reflexionando \\ bajo el punto de vista de la inclusión
}

Recebido: 31/05/2021 | Revisado: 07/06/2021 | Aceito: 09/06/2021 | Publicado: 21/06/2021

Mariana Santiago Tavares Corrêa
ORCID: https://orcid.org/0000-0003-0797-2753
Instituto Federal de Educação, Ciência e Tecnologia de Minas Gerais, Brasil
E-mail: mariana_santiago_tavares@hotmail.com
Raianny Kelly Nascimento Araújo
ORCID: https://orcid.org/0000-0001-9638-6216
Instituto Federal de Educação, Ciência e Tecnologia de Minas Gerais, Brasil
E-mail: raianny_kelly@hotmail.com

\begin{abstract}
Resumo
O Brasil é um país marcado por inúmeras desigualdades, além de episódios e narrativas de discriminação contra as múltiplas minorias, entre elas estão as mulheres. No âmbito dessa construção histórica e cultural, aos sujeitos femininos, resultam os processos discriminatórios e de objetificação. E quando essas mulheres trazem consigo alguma deficiência vivem uma dupla abjeção, tendo suas histórias marcadas pela invisibilidade e pela segregação social. Ao decidirem romper com o círculo vicioso da negação e ocuparem os diversos espaços, a exemplo ingressar nas universidades, se deparam com diferentes barreiras. Nesse sentido, buscamos analisar o acesso ao ensino superior e a conclusão dos estudos, oportunizado às mulheres com deficiência, a fim de compreender se estes espaços tem sido um mecanismo de garantia a autonomia e independência dessas mulheres. Realizamos este estudo em duas universidades localizadas em regiões diferentes do país, no Instituto do Noroeste Fluminense de Educação Superior (INFES/UFF), localizado na cidade de Santo Antônio de Pádua/RJ e na Universidade Federal de Pernambuco/Centro Acadêmico do Agreste (UFPE/CAA), localizada na cidade de Caruaru/PE. Dentre os resultados obtidos, evidenciamos que apesar de todo um arcabouço jurídico resguardando o acesso e permanência das pessoas com deficiências ao Ensino Superior, ainda há muitos avanços necessários, a fim de garantir a inclusão, de fato, dessas pessoas a esses espaços. E ao falarmos das mulheres com deficiências esses paradigmas da inclusão se maximizam ainda mais, pois sob elas recaem as diversas construções sócio- históricas que inibem a sua participação efetiva na sociedade e a efetivação dos seus direitos.
\end{abstract}

Palavras-chave: Mulheres; Deficiências; Inclusão; Ensino Superior.

\begin{abstract}
Brazil is a country marked by countless inequalities, as well as episodes and narratives of discrimination against multiple minorities, among them are women. In the context of this historical and cultural construction, the female subjects result in discriminatory and objectification procedures. And when these women bring with them some disability they live a double abjection, having their stories marked by invisibility and social segregation. By deciding to break the vicious circle of denial and to occupy the various spaces, such as joining universities, they face different barriers. In this sense, we seek to analyze the access to higher education and the conclusion of studies, which are timely for women with disabilities, in order to understand whether these spaces have been a mechanism for guaranteeing the autonomy and independence of these women. We conducted this study at two universities located in different regions of the country, in the Northwest Fluminense Institute of higher Education (INFES/UFF), located in the city of Santo Antonio de Padua/RJ and in the Federal University of Pernambuco/Agreste Academic Center (UFPE/CAA), located in the city of Caruaru/PE. Among the results obtained, we evidenced that, despite a legal framework, retaining the access and permanence of people with disabilities to higher education, there are still many necessary advances, in order to guarantee the inclusion, in fact, of these people to these spaces. And when we talk about women with disabilities, these paradigms of inclusion maximize even more, because under them are the various socio-historical constructions that inhibit their effective participation in society and the realization of their rights.
\end{abstract}

Keywords: Women; Deficiencies; Inclusion; Higher Education. 


\begin{abstract}
Resumen
Brasil es un país marcado por innumerables desigualdades, además de episodios y narrativas de discriminación contra las múltiples minorías, entre ellas están las mujeres. En el ámbito de esa construcción histórica y cultural, a los sujetos femeninos, resultan los procedimientos discriminatorios y de cosificación. Y cuando esas mujeres traen consigo alguna discapacidad viven una doble abyección, teniendo sus historias marcada por la invisibilidad y por la segregación social. Al decidir romper con el circulo vicioso de la negación y ocupar los diversos espacios, a ejemplo ingresar en las universidades, se encuentran con diferentes barreras. En este sentido, buscamos analizar el acceso a la enseñanza superior y la conclusión de los estudios, oportunizado a las mujeres con discapacidad, a fin de entender si estos espacios han sido un mecanismo de garantía la autonomía e independencia de esas mujeres. Realizamos este estudio en dos universidades ubicadas en regiones diferentes del país, en el Instituto do Noroeste Fluminense de Educación Superior (INFES/UFF), ubicado en la ciudad de Santo Antônio de Pádua/RJ y en la Universidad Federal de Pernambuco / Centro Académico del Agreste (UFPE/CAA), ubicada en la ciudad de Caruaru/PE. Entre los resultados obtenidos, señalamos que, a pesar de todo un marco jurídico de protección al acceso y permanencia de las personas con discapacidad a la enseñanza superior, todavía hay muchos avanzos necesarios, a fin de garantizar la inclusión, de hecho, de esas personas a esos espacios. Y al hablar de las mujeres con discapacidades esos paradigmas de la inclusión se maximizan aún más, pues bajo ellas recaen las diversas construcciones socio-histórica que inhiben su participación efectiva en la sociedad y la efectuación de sus derechos.
\end{abstract}

Palabras clave: Mujeres; Discapacidades; Inclusión; Enseñanza Superior.

\title{
1. Introdução
}

O processo de invasão, apropriação e violência, mais conhecido sob o significado de colonização, deixou-nos como herança, entre outras problemáticas, a forte influência do patriarcado e, por conseguinte, as violências que operam nas sutilezas do machismo estrutural (Andrade, 2017). Essa herança não somente resistiu ao longo de mais de cinco séculos de invasão, mas continua sendo predominante em todas as relações da sociedade. O Brasil, portanto, é um país marcado por inúmeras desigualdades, nossa história traz em seu bojo uma série episódios e narrativas de discriminação contra as múltiplas minorias, entre elas estão as mulheres caracterizada pela falta de equidade de gênero. São séculos de submissão e invisibilidade feminina, onde para estas, tradicionalmente, foi reservado o espaço privado, enquanto para os homens o espaço público (Scott, 1989).

Um olhar atento a esta história nos mostra diferentes movimentos e deslocamentos em torno do "ser mulher". Como sabemos, muitas conquistas foram realizadas em relação à questão da equidade de gênero, mas a associação da feminilidade à ideia de "fragilidade, beleza e cuidado com o outro" ainda permeia fortemente o imaginário social contemporâneo. Atrelado a essa trilogia, apresenta-se a afirmação de dependência da proteção masculina, da necessidade de cultuar o corpo e a plena realização por meio do casamento e da maternidade. Portanto, os corpos femininos, ao longo dos tempos, continuam perpassados pelas marcas da relação patriarcal, mediante a formação desta composição familiar sendo traduzida no "sentido sexual" (PATEMAN, 1993). Essas relações hierarquicamente constituídas, mantém-se sob argumentação da "lei do pai”, na dominação dos corpos, da vida e na privação de liberdade das mulheres. (Castro, 2012; Saffioti, 2004; Pateman, 1993).

Sobretudo, "ambos -controle e autoridade- são reafirmados e atualizados pelas sociedades patriarcais, por meio de dispositivos legais de controle e poder" (Andrade \& Corrêa, 2020, p.17). Portanto, as mulheres estão rodeadas de um discurso que tenta normatizá-las, em uma construção discursiva impregnada de estereótipos e atravessada por uma política de gênero. Como afirma Scott (1989, p. 19), o gênero é um "princípio elementar das organizações sociais e contribui na construção de papéis atribuídos a homens e mulheres, isto é, influencia as expectativas que criamos e as formas como lidamos com o outro". Sendo assim, é um elemento constitutivo das relações sociais, o qual se baseia nas diferenças percebidas entre os sexos. Na pauta destas perspectivas é relevante considerarmos que:

[...] essa maneira de olhar o corpo implica entendê-lo não apenas como um dado natural e biológico, mas, sobretudo, como produto de um intrínseco inter-relacionamento entre natureza e cultura. Em outras palavras: o corpo não é algo que está dado a priori. Ele resulta de uma construção cultural sobre a qual são conferidas diferentes marcas em diferentes tempos, espaços, conjunturas econômicas, grupos sociais, étnicos etc (Goellner, 2010, p. 73). 
No âmbito dessa construção histórica e cultural em relação aos corpos femininos, resulta nos processos discriminatórios e de objetificação das mulheres. Se olharmos para outra minoria social, a das pessoas com deficiência, iremos perceber também que estas têm uma história marcada pela invisibilidade e pela segregação social. Geralmente, foram e são percebidas como sujeitos "improdutivos, anormais, indesejados" e que precisam estar longe do convívio social. Dessa maneira, ser mulher com deficiência é viver uma situação de dúplice abjeção: "as mulheres com deficiência estão em dupla desvantagem devido a uma complexa combinação de discriminação baseada no gênero e na deficiência" (Mello \& Nuernberg, 2012, p. 639), são consideradas como "corpos desviantes" por subverterem os padrões hegemônicos de corpos "perfeitos, belos e saudáveis".

Entre tais efeitos, o preconceito é vivenciado de forma ainda mais intensa por essas mulheres. Este é um dos motivos que inibem sua inserção social, ocasionando o isolamento seguido da rejeição; a qual encontra-se quase sempre associada aos sentimentos de perda, desvalorização, falta de autoestima e/ou frustração. Essa subalternização das mulheres com deficiência, é um dos responsáveis pela estigmatização e exclusão social vivida por estas, diminuindo as redes sociais, as oportunidades e modificando a rotina diária destas pessoas (Araújo, 2017). Nesse sentido, buscamos com este trabalho compreender como se dá o acesso e a conclusão do ensino superior das mulheres com deficiências?

Assim, temos como objetivo analisar o acesso ao ensino superior e a conclusão dos estudos, oportunizando às mulheres com deficiência, a fim de compreender se este tem sido um mecanismo de garantir a autonomia e independência dessas mulheres. Portanto, delineamos enquanto objetivos específicos: (1) Traçar uma análise histórica dos paradigmas de gênero e da deficiência estabelecidos socialmente; (2) Levantamento do número de ingresso e conclusão dos cursos, de mulheres com deficiência na UFPE/CAA e na UFF/INFES nos últimos 10 anos; (3) Identificar as ações e propostas que as IES têm desenvolvido para garantir não só o acesso, mas a permanência e conclusão dos cursos nos quais essas mulheres estão inseridas, a fim de empoderá-las na construção da sua autonomia e independência.

\section{Percurso Metodológico}

Este trabalho se desenvolve a partir de pesquisas bibliográficas, a qual se baseia em materiais já publicados, que tem como finalidade o fundamento para a contextualização do campo teórico, já que de acordo com Gil (2010), nos permite construir visões amplas dos fenômenos da pesquisa. Estabelecemos como abordagem, a pesquisa qualitativa, que segundo Creswell (2012) considera os passos procedimentais singulares e de diferentes estratégias. Assim sendo, a abordagem utilizada para obtenção dos dados foi análise documental, que segundo Ludke e Andre, embora seja pouco explorado na área de educação, este "pode se constituir numa técnica valiosa de abordagem de dados qualitativos", principalmente desvelando novas perspectivas acerca da temática abordada (2013, p.38).

A partir desse levantamento de dados, por meio da pesquisa documental, buscamos identificar quantas mulheres com deficiência ingressaram e conseguiram se formar nas Instituições de Ensino Superior. Com foco nas instituições localizadas nos micro-lugares, sendo estas o Instituto do Noroeste Fluminense de Educação Superior (INFES/UFF), localizado na cidade de Santo Antônio de Pádua/RJ e a Universidade Federal de Pernambuco/Centro Acadêmico do Agreste (UFPE/CAA), se localiza na cidade de Caruaru/PE.

Escolhemos esses dois campos de pesquisa, pois são instituições que fazem parte das nossas trajetórias formativas e de pesquisas. Tivemos a oportunidade de estudar nesses espaços e vivermos os processos de interiorização da universidade pública e com ele todos os desafios inerentes, e a partir daí podemos identificar o quanto os processos de inclusão ainda são tímidos nesses espaços, o que justifica produções como este trabalho, o qual busca colocar luz aos desafios para que a partir disso, os direitos possam - de fato- serem efetivados, contribuindo assim para o desenvolvimento profissional e social das mulheres com deficiências em nossas localidades. 
Os dados analisados nos foram cedidos pelo Núcleo de Acessibilidade (NACE) da UFPE/CAA, os quais apresentam os números de matrículas realizadas no Centro Acadêmico de pessoas com e sem deficiências, assim como o número de pessoas e os respectivos anos de conclusão dos cursos de graduação. Já a informação de que o INFES/UFF não acompanha esses registros nos foi dada pela secretaria da instituição.

$\mathrm{Na}$ descrição dos resultados propomos estabelecer uma relação desde os objetivos traçados e as considerações das coletas documentais, a fim de identificar as potencialidades e as fragilidades das IES na inclusão, permanência e condições de formação para essas mulheres com deficiência. A análise dos dados se dará pelo método da análise de conteúdo, de acordo com Bardin (1977) o qual nos permite analisarmos os dados coletados em profundidade e a partir daí tecer considerações mediante os nossos objetivos propostos neste trabalho. Para além disso, este artigo se circunscreve enquanto espaço-tempo de construção epistêmica de denúncias e buscando a reparação das violências no ingresso e permanência das mulheres com deficiência no ensino superior.

\section{Gênero e Deficiência: Reflexões Sobre Inclusão, Autonomia e Empoderamento}

\subsection{As pessoas com deficiência na sociedade: uma incursão histórica}

Ao tentarmos iniciar uma breve introdução na história da humanidade, podemos identificar que a forma de nomear/caracterizar a pessoa com deficiência, vem se distinguindo ao longo do tempo. "A visão sobre a deficiência nem sempre foi a mesma e muda conforme a cultura, o tempo e o espaço" (Rossi, 2020, p.3). Da mesma forma, o processo dessa construção histórica é perpassado por diversos avanços e retrocessos, que permeiam a sociedade e o mundo como um todo.

No Egito Antigo, a deficiência era considerada um dom e quem a possuía tornava-se divino. Já na no contexto da Grécia e Roma, na mesma época, a deficiência partia da conviç̧ão como provocadora de futuros males, por este motivo as crianças com deficiência eram jogadas da Rocha da Tarpeia ou abandonadas. Já na Idade Média, o que regia a sociedade era a religião, portanto, a deficiência era tida proveniente de forças demoníacas, e como a alusão era o Divino, acreditava-se que somente os "perfeitos" seriam criaturas "semelhantes a Deus" (Mazzota, 1996). Portanto, aqueles que eram considerados "imperfeitos" eram correlacionados ao diabo e dessa forma sofriam perseguição e até mesmo execução.

Ao longo dos séculos, as formas de compreender a deficiência foram tomando outras perspectivas. Nos tempos medievais, foram construídos - pelos nobres algumas ordens religiosas- alguns hospícios e albergues para acolher deficientes e marginalizados. Mas, ainda assim, se perdurava a ideia de que as pessoas com deficiência poderiam apresentar alguma ameaça (Silva, 2009). No período que marcou a Era Moderna, o Renascimento, trouxe algumas transformações em diversos âmbitos e também uma nova perspectiva ao tratamento destas pessoas, considerados para alguns como significativos e positivos. "Surgiram hospitais e abrigos mais humanizados e começaram a surgir descobertas relevantes no tratamento de determinadas deficiências" (Rossi, 2020, p. 4).

Sobretudo, mesmo com o possível surgimento de avanços, a deficiência ainda enfrentava/enfrenta muitos estigmas. E ao longo dos anos, especificamente no decorrer do século XIX e início do século XX, o assistencialismo passou a surgir no cenário de atendimento às pessoas com deficiências. Dessa forma,

Essa assistência era dada em instituições construídas longe das cidades, o que tornava os assistidos distantes da sociedade, sem poderem se comunicar e sem liberdade. A partir da segunda metade do século XIX, surgiu a preocupação com a necessidade de atenção especializada às pessoas com deficiência, não unicamente em abrigos e hospitais. Com as concepções pós-renascentistas e as transformações sociais que aconteceram na Europa com a colaboração dos estudos de Esquirol, a diferenciação entre deficiência mental e doença mental começa a surgir. Na mesma época, alguns médicos educadores como Itard, Seguin e Maria Montessori desenvolveram pesquisas relevantes para a educação de pessoas com deficiência (Rossi, 2020, p. 4). 
Sendo assim, mais especificamente no Brasil, Dom Pedro II fundou importantes centros no tratamento de cegos e surdos. Até os dias atuais estão em atividade: o Imperial Instituto dos Meninos Cegos (1854), hoje chamado Instituto Benjamin Constant; e o Imperial Instituto dos Surdos Mudos (1857), hoje denominado Instituto Nacional de Educação de Surdos - INES. Mesmo mediante esses acontecimentos, somente começam a surgir, de fato, ações e medidas efetivas "em busca de um melhor atendimento, proteção e inclusão da pessoa com deficiência na sociedade, no século XX” (Rossi, 2020, p. 4).

Para além disso, várias conferências e congressos começaram a ocorrer em diversos países. Mas, um novo cenário surge durante este percurso e põe em jogo todo o avanço. A primeira e a segunda guerra mundial propiciam a interrupção de todas as conquistas que começaram a ganhar forma desde então. $\mathrm{O}$ alto número de pessoas mutiladas na guerra, ocasionou o aumento da população com deficiência ao redor de todo o mundo. Na segunda guerra este retrocesso foi ainda mais desastroso, no dia primeiro de setembro de 1939, "Adolf Hitler instaura o Programa de Eutanásia na Alemanha nazista (1939 a 1941), que teve como objetivo a eliminação de doentes incuráveis, idosos senis, deficientes físicos e doentes mentais” (Rossi, 2020, p. 5).

Foi estimado que 275 mil adultos e crianças com deficiência tenham sido assassinados durante este período. E cerca de 400 mil pessoas foram esterilizadas por serem suspeitas de terem hereditariedade de cegueira, surdez e deficiência mental, a fim de manter a raça ariana pura (Gugel, 2008). Após o fim da Segunda Guerra Mundial, deu-se início a uma maior conscientização da necessidade de tomar medidas, a fim de extinguir as atrocidades ocorridas durante a guerra de modo que estas não mais se repetissem ao longo da história. E assim também surge a discussão para reabilitação das pessoas vítimas dos combates.

Além dessas iniciativas, dá-se início também a um movimento de consolidação de direitos. E neste período surge a Organização das Nações Unidas - ONU, em 1945, em Londres, com intuito de lutar pela paz entre as nações. E em 1948, foi elaborada a Declaração Universal dos Direitos Humanos, em 1948, que se destaca pelo fato de fazer menção expressa à pessoa com deficiência. Portanto, tal documento fundamentava o direito a todas as pessoas e direitos decorrentes, como afirma a Declaração Universal dos Direitos Humanos, no artigo 1 ${ }^{\circ}$ : "Todos os seres humanos nascem livres e iguais em dignidade e direitos. São dotados de razão e consciência e devem agir em relação uns aos outros com espírito de fraternidade" (Assembleia Geral da ONU, 1948).

A Declaração carrega um valor inestimável, que influenciou posteriormente outros documentos importantes para a temática, e além disso esta também motivou a criação de novas instituições e consolidação das já existentes, que visavam a concretização da inclusão social destes sujeitos (Dicher \& Trevisam, 2018). E assim, após o início dos anos 50, gradativamente foram surgindo em várias partes do mundo, instituições voltadas ao atendimento e tratamento específico de pessoas com deficiência, "principalmente buscando alternativas para sua integração social e aperfeiçoamento das ajudas técnicas para pessoas com deficiência física, auditiva e visual" (Gugel, 2007).

Como é perceptível, são séculos de silenciamento e apagamento das pessoas com deficiência ao longo da história da humanidade, é sabido que na contemporaneidade muitas já foram as conquistas para essa parcela da população. Contudo, temos vivido em nosso país alguns retrocessos no que tange a direitos já adquiridos historicamente e sabemos também, que a efetividade dos serviços ou a garantia desses ainda é escassa em muitos lugares do Brasil. Precisamos ter em mente todos os processos e marcos históricos de segregação e exclusão destas pessoas, para seguirmos lutando pela garantia dos seus direitos, na defesa das suas dignidades, para seguirmos avançando na construção de uma sociedade cada vez mais justa.

\subsection{Os paradigmas de gênero e a mulher com deficiência}

Abordando essa discussão de deficiência para a categoria de gênero, é imprescindível perceber que dentro do grupo das pessoas com deficiência estão as mulheres, sendo recorrentemente atingidas por diversos estereótipos e práticas discriminatórias, duplamente, ao se que refere ao gênero e a deficiência. Essa afluência discriminatória acaba reverberando em diversas barreiras atitudinais, marcadas pela sociedade machista e patriarcal, na qual estamos inseridas. Estas mulheres com deficiência além de 
terem que enfrentar essas barreiras colocadas pelas marcas da misoginia, ainda enfrentam maiores discriminações do que qualquer outra mulher para ingressar no ensino básico ou superior (Araújo, 2017).

A estas mulheres com deficiência é reservado um processo de estigmatização que proporciona identificações sociais que as segregam socialmente, de acordo com Silva (2006):

O estigma, por ser uma marca, um rótulo, é o que mais evidencia, possibilitando a identificação. Quando passamos a reconhecer alguém pelo rótulo, o relacionamento passa a ser com este, não com o indivíduo. [...] Nesse processo de rotulação, o indivíduo estigmatizado incorpora determinadas representações, passa a identificar-se com uma tipificação que o nega como indivíduo (Silva, 2006, p. 427).

As mulheres com deficiência passam a ser percebidas e identificadas por essas diferenças tidas como negativas ou distantes da "normalidade". A partir desse entendimento do tema, a proposição deste trabalho busca investigar a inclusão dessas mulheres nas Instituições de Ensino Superior, analisando principalmente as diferenças e paradigmas que existem entre a integração e inclusão destas. Pensando nas possibilidades dos processos educativos enquanto elemento de autonomia, empoderamento e inclusão dessas mulheres, a partir da garantia do acesso e permanência no processo de sua formação. Compreendendo que "a Educação Inclusiva é antes de tudo uma questão de direitos humanos" (Sanchéz, 2005, p.10).

Levando em consideração estes apontamentos, percebe-se que universalmente temos sido levadas a pensar em uma categoria universal de mulher, principalmente sob a mulher com deficiência, desconsiderando todas as outras possibilidades e pluralidades dos sujeitos que compõem esse grupo. As mulheres que não se enquadram no padrão universal, geralmente, são tratadas como abjeto. Nesse sentido, as mulheres com deficiência, por não se encaixarem nos padrões hegemônicos de feminilidade, normalmente são silenciadas e invisibilizadas. Segundo Louro (2010, p.14): "os corpos são significados pela cultura e são, continuamente, por ela alterados", nos fazendo refletir sobre a influência da cultura na construção desses corpos.

Nessa perspectiva, Butler (2010) nos oferece conceitos importantes para pensarmos a construção dos padrões relacionados ao corpo. Traz para o debate a ideia de "performatividade" e de corpo "abjeto". Apesar da autora não tratar de corpos com deficiência é possível estabelecer essa relação. Para ela, a performatividade são normas regulatórias, que produzem, materializam, constroem os corpos: "a performatividade deve ser compreendida não como um "ato" singular ou deliberado, mas, em vez disso, como prática reiterativa e citacional pela qual o discurso produz os efeitos que ele nomeia" (Butler, 2010, p. 154). Assim se constitui a "fixidez" do corpo. Portanto, tudo além do estabelecido é visto como subversivo, sendo estranho, grotesco, indesejável. A essas possibilidades negadas e estranhas, Butler (2010), nomeia de "abjeto":

Esta matriz excludente pela qual os sujeitos são formados exige, pois, a produção simultânea de um domínio de seres abjetos, aqueles que ainda não são "sujeitos", mas que formam o exterior constitutivo relativamente ao domínio do sujeito. O abjeto designa aqui precisamente aquelas zonas "inóspitas", "inabitáveis" da vida social, que são não obstante, densamente povoadas por aqueles que não gozam do status de sujeito (Butler, 2010, p. 155).

Como bem explora Butler (2010), a norma que ela chama de matriz, ao produzir o corpo perfeito, cria em oposição o "imperfeito", este será negado, silenciado e habitará o local do não desejável, mas este local é necessário para que dali ele reivindique seu direito de existir. Esse direito de existir é questionado rotineiramente por essas mulheres, nos mais diversos espaços habitados e ocupados por estas, nas Instituições de Ensino não é diferente, as mulheres com deficiência vivem com os processos de exclusão cotidianamente e o seu percurso formativo é repleto de obstáculos que por muitas vezes, nem as permitem adentrar ao nível superior de ensino.

Nesse sentido, precisamos oportunizar esses espaços, quebrar as barreiras não só atitudinais e arquitetônicas, mas todas aquelas que possam impedir a inclusão, de fato, dessas pessoas, ampliando as fronteiras interseccionais, transversais e transdisciplinares, a fim de criarmos condições nas IES, que possam garantir "o máximo desenvolvimento possível de seus 
talentos e habilidades físicas, sensoriais, intelectuais e sociais, segundo suas características, interesses e necessidades de aprendizagem" (Brasil, 2015).

\subsection{O acesso das mulheres ao ensino superior e os desafios das mulheres com deficiência}

É imprescindível a percepção das desigualdades de gênero estabelecidas, sobretudo, a partir das relações construídas socialmente nas determinações entre os sexos. Estas estão perpassadas mediante a realidade das sociedades ocidentais e ao longo dos tempos. Nesses desdobramentos, vemos a resistência das diferentes manifestações perpetuando-se no mundo contemporâneo em que as mulheres permaneceram subjugadas a um papel normativo imposto pela sociedade patriarcal.

Não abstendo essa lógica, as mulheres com deficiência enquanto sujeitos históricos e parte dessas relações sociais, dentre as distintas classes sociais e culturais permeiam ainda mais a relação com o estigma e subjugação. Portanto, os preconceitos e discriminações enfrentados por estas, tornam-se ainda mais desumanos e tirânicos.

É a partir desse entendimento que compreendemos a educação enquanto um agente de transformação e mediador no processo de socialização humana, podendo assim ser um contributivo para elementos de mudanças coletivas e individuais. E deste modo fortalece enquanto uma possível rede de apoio constituída a fim de empoderar as mulheres com deficiência na construção da sua autonomia e independência. Sabemos que o direito à educação é um direito constituído e o acesso/permanência se torna um fator básico na constituição desse direito.

A relevância dada ao conceito de inclusão se circunscreve na discussão permeada por estigmas e desigualdade. Justamente pelo fato deste ainda ser caracterizado por paradigmas que existem entre integração e inclusão, diante de uma perspectiva histórica. Observamos que:

Existe uma distorção do conceito de inclusão voltada para o uso do vocábulo "integração". Essa integração tem o sentido de inserir os alunos com deficiências nas escolas regulares, mas sem uma proposta pedagógica e estrutural diferenciada. E é justamente essa indiferenciação entre o processo de integração e de inclusão escolar que, muitas vezes, reforça atitudes baseadas no paradigma tradicional no interior da escola (Rossi, 2020, p. 2).

Assim como acontece nas escolas, os diversos espaços sociais não estão preparados para viver a inclusão, de fato, pois não há mudanças estruturantes que permitam aos sujeitos sentirem e perceberem que esses espaços foram pensados e construídos para abraçar todas as diferenças e diversidades que nos permeiam enquanto sujeitos. O que acaba acontecendo é a necessidade das pessoas com deficiência precisarem se adequar a estes espaços, o que resulta em uma ação integracionista e não inclusiva. Com isso, os âmbitos educacionais que precisam ser espaços efetivos para acolher a diversidade, vão criando -intencionalmente ou não- "mecanismos de expulsão compulsória" desses sujeitos, por isso que se torna tão difícil as pessoas com deficiência, e principalmente as mulheres, por toda história que já apresentamos aqui, adentrarem ao nível superior de ensino e nele permanecerem (Melo Lopes, 2018).

Mediante isso, a importância do entendimento que diante do contexto histórico e político brasileiro, a Educação Especial foi predominantemente segregacionista, sendo redirecionada para a dimensão de separação da educação das pessoas com deficiências do ensino comum, para a politização de todos serem educados de forma imediata (Mendes, 2006). Isso refletiu na realidade na qual nos perpassa atualmente, uma educação que está aberta a todos os sujeitos independentemente de suas necessidades, no que abrangesse uma educação especial em todos os níveis e modalidades de ensino (Rossi, 2020). Dessa forma, o surgimento da educação inclusiva ocorreu em torno dos anos 80 e 90, com a mobilização internacional de pais, profissionais e pessoas com deficiência, que lutavam contra a ideia de educação especial.

Cabe evidenciar que o ponto mais exato de onde surge o movimento, ocorreu nos Estados Unidos, denominado como "Regular Education Iniciative” (REI), ao qual o objetivo principal era a inclusão de crianças com deficiência na escola comum. Desta forma, a ideia crucial era unificar a educação especial ao ensino regular em um mesmo sistema educativo, objetivando 
também fazer uma crítica à ineficiência da educação especial. "A proposta do REI é clara: todos os alunos, sem exceção, devem estar escolarizados na classe de ensino regular, e receber uma educação eficaz nessas classes” (Sanchéz, 2005, p.8).

Em prol da mobilização da educação inclusiva nas escolas houveram diversas movimentações advindas de organismos internacionais, conferências, convenções, fóruns, dentre estes cabe destacar a Conferência Mundial sobre Necessidades Educativas Especiais, de 1994, ocorrida em Salamanca, na qual merece destaque por ser uma das maiores mobilizações, que acarretaram de maneira decisiva, contribuindo para o reconhecimento urgente de que o ensino chegasse a todas as crianças, jovens e adultos com necessidades especiais. Isto posto, ficou estabelecido um plano de que as escolas deveriam acolher a todas as crianças, independentemente de suas condições físicas, intelectuais, sociais, emocionais, linguísticas e outras. Assim a declaração determinou um catálogo de recomendações para que os países participantes pudessem seguir com os preceitos: requerer, aplicar, reconhecer e realizar a inserção da Educação Inclusiva em todo o mundo. Partindo do pressuposto que:

[...] a inclusão consiste em adequar os sistemas sociais gerais da sociedade de tal modo que sejam eliminados os fatores que excluíam certas pessoas do seu seio e mantinham afastadas aquelas que foram excluídas. A eliminação de tais fatores deve ser um processo contínuo e concomitante com o esforço que a sociedade deve empreender no sentido de acolher todas as pessoas, independentemente de suas diferenças individuais e das suas origens na diversidade humana (Sassaki, 2005, p.21).

É importante ressaltar as diferenças e paradigmas que existem entre integração e inclusão, diante de uma perspectiva histórica (Sassaki, 2005). Pode-se afirmar que o termo inclusão surgiu como uma forma de alternativa à integração, ou seja, como uma forma de denunciar e eliminar as situações de desintegrações e exclusão ocorridas (Sanchéz, 2005). Portanto, a ideia concebida sobre inclusão e integração, relata que o princípio da integração buscava "normalizar" os alunos. Ou seja, a integração e a inclusão, se diferem no sentido de que a integração visa colocar o aluno em segundo plano.

Sobretudo, o papel da inclusão cabe englobar a todos os alunos, não somente a alunos com necessidades especiais como certamente enfatizavam anteriormente. Portanto, pode-se afirmar que o termo inclusão surgiu como uma forma de alternativa à integração, ou seja, como uma forma de denunciar e eliminar as situações de desintegrações e exclusão ocorridas. Desta forma, como uma maneira de reconstruir os discursos de indivíduos deficitários. E por último vem como uma reivindicação para todos os sujeitos com ou sem necessidades especiais, para que todos tenham educação de qualidade, diante do sistema regular do ensino (Sanchéz, 2005).

Mediante estes aspectos, ressalta-se, que somente no início da década dos anos 90, que o universo da educação tomou um novo caminho para uma escola de qualidade e realmente aberta para todas as pessoas. Deste modo, esta nova perspectiva denominada de educação inclusiva se difere das outras formas concebidas anteriormente de inserção escolar de pessoas com deficiência, a qual apenas visava integrar este aluno. Sendo assim, o surgimento da inclusão e suas abordagens e fundamentos, tende a diferenciar a discussão sobre a educação inclusiva. Através disso, cabe destacar que, começam a surgir então os assuntos dentro da perspectiva da diversidade, no âmbito da educação inclusiva, "a não discriminação das deficiências, da cultura e do gênero" (Sanchéz, 2005, p.7).

Esta vertente da inclusão não somente restringe a educação escolar básica, mas atravessa também as IES. Trazendo em pauta a garantia de direitos à pessoa com deficiência em toda trajetória educacional. A fim de garantir-lhes também o acesso e permanência ao ensino superior. Portanto, sabemos de todas as barreiras que as mulheres com deficiência enfrentam, decorre-se da ausência de efetividade dessas garantias.

Partindo desses pressupostos, o posicionamento assumido neste estudo não pretende traçar um quadro detalhado da história das políticas públicas da inclusão das mulheres com deficiência, mas analisar os contextos que possibilitam identificar a construção da trajetória de acesso e permanência nas IES. 


\section{Resultados e Discussões}

É sabido que a universidade pública tem em sua origem a necessidade de ser um espaço plural, aberto e democrático, pelo qual as diversas diferenças possam ser acolhidas. Sabemos ainda que essa não é uma tarefa fácil, principalmente no nosso país, a começar pelo formato de ingresso a esse espaço, o qual se pauta em processo seletivo. Esse é o primeiro desafio posto na universidade, pois ela precisa articular a democratização do acesso, ao mesmo tempo em que precisa garantir a qualidade do ensino superior a todos(as) os(as) alunos, inclusive os(as) alunos(as) com deficiência.

Além disso, quando analisamos a concepção da educação básica, ela está descrita na lei como um mecanismo de assegurar a todos a formação comum indispensável para o exercício da cidadania, conforme o art. 43 da LDB (Lei no 9.394, 1996), já uma das finalidades da educação superior, se não a mais valorizada na contemporaneidade, é formar diplomados nas diferentes áreas de conhecimento, aptos ao ingresso no mundo do trabalho. O qual por diversas vezes coloca-se como um lugar de exclusão e segregação para as pessoas tidas como "diferentes do padrão".

Nessa perspectiva, é requerido das universidades a necessidade de reinventar-se e considerar as especificidades demandadas pela inclusão, a fim de garantir não apenas o acesso, mas a permanência desses sujeitos dissidentes e mais tarde também, a sua inserção qualitativa no mundo do trabalho. Isso demanda a estas instituições transformações complexas na estrutura e no funcionamento, desde as suas estruturas arquitetônicas, curriculares e consequentemente a forma de pensar e de agir dos seus professores e funcionários. Como coloca Moreira, Bolsanello e Seger (2011),

Uma universidade inclusiva só é possível no caminhar em busca da mudança que vai eliminando barreiras de toda ordem, desconstruindo conceitos, preconceitos e concepções segregadoras e excludentes. É um processo que nunca está finalizado, mas que, coletivamente, deve ser constantemente enfrentado (Moreira, et al., 2011, p. 141).

Assim, o paradigma da inclusão requer um modelo de ensino superior que, historicamente, formava profissionais com base na seleção e na competitividade, um ensino que gere o acolhimento de todos(as) os(as) alunos(as) indistintamente, atendendo suas especificidades para aprender, garantindo-lhes a acessibilidade necessária. Tornando esses espaços educacionais em redes de sororidade, acolhimento e empatia. Possibilitando mudar exponencialmente as realidades perversas que dizem respeito ao acesso e permanência das mulheres nessas instituições.

Pois, ao analisarmos os dados de acesso às universidades públicas por meio do Instituto Nacional de Estudos e Pesquisas (Inep), dados divulgados no resumo técnico do último Censo da Educação Superior (2019), têm-se 2.080.146 estudantes brasileiros que efetuaram matrículas em Instituições Públicas de Ensino Superior, em 2019. Deste número, 48.520 declararam apresentar alguma necessidade especial constitutiva do público-alvo da educação especial, ou seja, alunos com deficiência, transtornos globais de desenvolvimento e altas habilidades/superdotação. Destes, as três maiores populações compreendem-se: alunos com deficiência física contabilizando 16.376; com baixa visão um total de 13.906 e deficiência auditiva um número de 6.569 .

Quando olhamos para os números do ano de 2010, o que compreende o último decénio do censo, tínhamos naquele ano 19.869 alunos que declararam ter alguma deficiência, o aumento expressivo dos números de matrículas se comparado ao ano de 2019, tem aliado à questão legal, a Política Nacional de Educação Especial na perspectiva da Educação Inclusiva, aprovada em 2008 (Brasil, 2008), que propõe a transversalidade da educação especial também no ensino superior. Contudo, não são todas as universidades que têm cumprido as orientações e normativas legais existentes, pois trata-se de um processo que demanda mudanças complexas e por isso acontece a passos lentos (Moreira, et al., 2011).

Nesse sentido, um dos locus da nossa pesquisa o Instituto do Noroeste Fluminense de Educação Superior (INFES/UFF), infelizmente, não dispõe de dados de registros oficiais quanto a uma política estruturada a respeito da inclusão das pessoas com deficiências no instituto. Ao contatarmos os setores responsáveis pelas matrículas dos(as) estudantes, foi nos informado não 
haver um sistema que dê conta de identificar quais e quantos(as) são os(as) alunos(as) que têm algum tipo de deficiência, o que nos aponta um desafio enorme para inclusão destas pessoas nesse espaço, já que este seria o primeiro passo para construir ações efetivas para acessibilidade e inclusão. O trabalho acaba sendo efetuado somente pelos secretários dos cursos em buscas de relatórios de entradas pelas Ações Afirmativas de reserva de vagas para alunos com deficiência. Somente o curso de Pedagogia que encontrou um aluno nos relatórios com entrada em 2019.

Mesmo com uma série de arcabouços legislativos que asseguram a inclusão deste público no ensino superior, desde a nossa Constituição Federal (1988); a Lei Brasileira da Língua de Sinais de n 10.436/2002; a Lei no 10.098/2000 tida como Lei de Acessibilidade, além da implementação de programas governamentais de educação inclusiva voltados especificamente ao ensino superior, entre eles é possível citar: o Programa Universidade para Todos - PROUNI, o Plano de Reestruturação e Expansão das Universidades Federais - REUNI, e especificamente o Programa de Inclusão no Ensino Superior - INCLUIR, que tem por objetivo garantir o direito da pessoa com deficiência à educação superior, fomentando a criação e a consolidação de núcleos de acessibilidade nos Institutos Federais de Ensino Superior, visando possibilitar a criação de ações institucionais nas universidades para integrar as pessoas com deficiência e eliminar as barreiras arquitetônicas, de comunicação, pedagógicas e/ou comportamentais, que venham a existir, temos muitos casos assim como o do INFES/UFF, o qual não conseguimos encontrar ações voltadas à inclusão deste público.

No nosso outro locus de pesquisa, a Universidade Federal de Pernambuco- CAA, tem instaurado o Núcleo Setorial de Acessibilidade do CAA tem por finalidade auxiliar o Núcleo de Acessibilidade da UFPE - NACE. O qual se propõe a realizar o atendimento aos discentes, docentes e técnicos administrativos em educação do CAA, com deficiência, transtorno global do desenvolvimento, transtorno funcional específico da aprendizagem, altas habilidades/superdotação e redução de mobilidade quanto ao seu acesso e permanência com qualidade na UFPE.

De acordo com o próprio núcleo, esta busca desenvolver o atendimento ao público alvo: "mediante a efetivação de ações que visem eliminar barreiras atitudinais, arquitetônicas, comunicacionais, metodológicas, instrumentais, programáticas que restringem a participação e o desenvolvimento acadêmico e profissional” (UFPE, 2020), o núcleo foi instituído apenas no ano de 2016 e tem as suas atividades regulamentadas pela Portaria Normativa 04/2016.

Ainda de acordo com as informações do núcleo, eles têm como objetivos:

- Promover a inclusão, a permanência e o acompanhamento de pessoas com deficiência e necessidades específicas, nos diversos níveis de ensino oferecidos por esta instituição, garantindo condições de acessibilidade na UFPE;

- Articular-se intersetorialmente frente às diferentes ações já executadas na UFPE, assim como na promoção de novas ações voltadas às questões de acessibilidade e inclusão educacional, nos eixos da infraestrutura; comunicação e informação; ensino, pesquisa e extensão;

- Oferecer Atendimento Educacional Especializado (AEE), a partir de uma equipe multidisciplinar, voltado para seu público-alvo;

- Constituir parcerias com entidades governamentais e sociedade civil organizada, cujos objetivos tenham relações diretas com as finalidades do NACE/UFPE (UFPE,2020).

Como já citado, este é um campus relativamente novo, com apenas 15 anos de existência e somado a isto sabemos de todos os desafios para a implementação das políticas públicas para a inclusão. Reconhecemos que é um avanço significativo termos em um instituto jovem a implementação de uma iniciativa como o NACE, mas ao analisarmos os números de matrículas, comparadas ao número de mulheres que conseguem concluir os cursos percebemos o quanto este público ainda carece de ações mais assertivas e que potencializam cada vez mais a inclusão via permanência qualitativa neste espaço. Podemos ver a seguir o 
gráfico da UFPE/CAA que demonstra o quantitativo de alunos com deficiência matriculados entre os anos de 2010-2020:

Figura 1 - Alunos matriculados na UFPE/CAA, 2020.

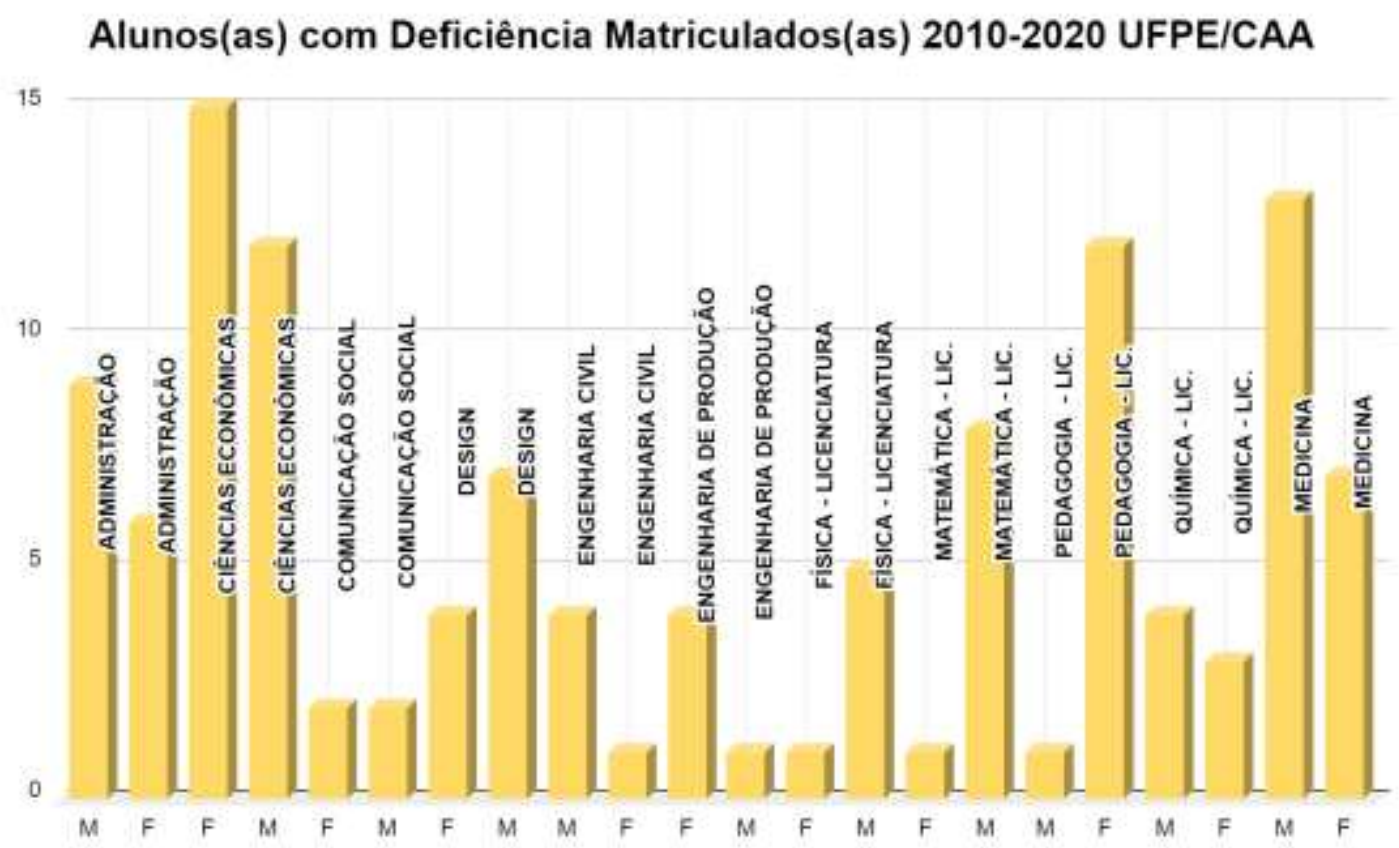

Fonte: NACE/UFPE (2020).

Ao analisarmos os números temos entre os anos de 2010 a 2020 um total de apenas, $\mathbf{1 2 2}$ alunos(as) com deficiências matriculados em todos os cursos disponíveis na UFPE/CAA, deste 56 são do sexo feminino e $\mathbf{6 6}$ do sexo masculino. Do universo de 122 estudantes, apenas 29 destes conseguiram concluir o curso no intervalo temporal mencionado. $\mathrm{O}$ que nos chama atenção é que destes 29, temos 18 mulheres, o que confirma que as mulheres, mesmo acumulando tantos outros papéis sociais e ainda carregando consigo os paradigmas das deficiências, ainda conseguem conquistar este espaço mais que os homens.

Nesse sentido, os dados nos apontam que há cada vez mais a necessidade de se investir em políticas inclusivas que possam possibilitar a todos e a todas não apenas ingressarem, mas concluírem com autonomia e dignidade o nível superior de ensino, pois olhando de maneira isolada para os números da UFPE/CAA temos, só aqui, 93 pessoas que "ficaram para trás". Sem falar no número de ingressantes que ainda é muito baixo, se fizermos uma média simples a taxa de ingresso é de apenas 12,2\%. Sabemos ainda, que há um universo gigantesco de pessoas com deficiências que não conseguem nem concluir a educação básica, tendo assim seus direitos inalienáveis ainda mais negados.

\section{Algumas Considerações Finais}

Às mulheres com deficiências são reservados inúmeros desafios, desde "ser mulher" e exercer os diversos papéis possíveis na sociedade, já que são rodeadas de inúmeros preconceitos e paradigmas que inibem a sua inserção social e minimizam as oportunidades que estas podem vir a ter. Quando estas mulheres optam por estudar e desenvolver-se profissionalmente se deparam com múltiplas dessas barreiras, principalmente a da ausência da acessibilidade e de condições plenas para aprender com autonomia.

Na introdução deste trabalho anunciamos que tínhamos como objetivo analisar o acesso ao ensino superior e a conclusão dos estudos, oportunizando às mulheres com deficiência, a fim de compreender se este tem sido um mecanismo de garantir a 
autonomia e independência dessas mulheres. Para isso, construímos uma análise histórica dos paradigmas de gênero e da deficiência estabelecidos socialmente e a partir daí, realizamos o levantamento do número de ingresso e conclusão dos cursos, de mulheres com deficiência nos nossos dois campos de pesquisa escolhidos, a UFPE/CAA e a UFF/INFE. A partir dos dados coletados foi possível evidenciar que as iniciativas, quando existentes, para garantir o acesso e principalmente a permanência dessas mulheres ao ensino superior, ainda são tímidas e/ou pouco efetivas e acabam por não garantir que todas as mulheres com deficiências que entram a universidade consigam concluir, já que aproximadamente, apenas, 30\% das mulheres que adentraram em uma das instituições conseguiram concluir o seu curso. Sabemos que há múltiplos fatores que podem acarretar a não conclusão dos cursos, entre eles fatores que podem nem ser de responsabilidades das instituições, mas os baixos índices de acesso já denotam para nós o quanto o nosso país e as universidades públicas precisam ser espaços cada vez mais inclusivos.

Sabemos que as condições de acesso e permanência a pessoa com deficiência no ensino superior não implica apenas a construção de espaços fisicamente acessíveis, mas também recursos pedagógicos e didáticos, informações para a comunidade técnico-administrativa, formações para o corpo docente e apoio institucional, além das mudanças dos próprios paradigmas ideológicos. Portanto, há que se proporcionar uma mudança conjuntural na forma de funcionar das instituições, não apenas no ensino, mas também na maneira de fazer pesquisa e extensão, bem como na infraestrutura oferecida a toda a comunidade acadêmica. Compreendemos que tornar a universidade um espaço verdadeiramente inclusivo é uma tarefa complexa, principalmente em um país como o nosso, onde cada vez menos temos a valorização e os investimentos necessários nesta área.

Uma universidade, verdadeiramente inclusiva, requer a construção de múltiplas ações intersetoriais e multidisciplinares que sejam pautadas na eliminação de todos os tipos de barreiras que possam dificultar ou impedir a plena participação dessa população nas diferentes esferas. Para além disso, o propósito deste trabalho, circunscreve-se no sentido de possibilitar a construção deste estudo enquanto espaço-tempo de denúncias e pensando possíveis reparações para a realidade vivenciada pelas mulheres com deficiência no ensino superior. Destacamos, que dentro das possibilidades, tentamos traçar um breve contexto histórico em paralelo com os avanços na legislação, e sobretudo, confrontando as realidades e fragilidades encontradas nas intuições pesquisadas.

Logo, sabemos que mediante este estudo foi possível propiciar ações de futuras reparações aos atos de negligência presentes nas relações sociais das mulheres com deficiência. Nesse sentido, a relevância desse estudo se concretiza, entre diversas perspectivas, em principalmente confrontar os contextos sociais mediante as barreiras da discriminação baseada no gênero e na deficiência nos espações educacionais do ensino superior.

Em nossa compreensão, consideramos que a pesquisa se desdobra para além dos objetivos propostos e tomam olhar minuciosos para a garantia de direitos. Traçando desde então novas oportunidades de construir elementos educacionais, sociais e políticos em prol da reparação das linhas de dupla violência secularmente impostas às mulheres com deficiência.

Assim sendo, o âmbito da pesquisa se encontra enquanto estimulo de buscarmos nos diversos ambientes sociais, dentro e fora da academia as seguintes premissas: a) confrontar a problemática em todos os âmbitos sociais e políticos; b) garantir os direitos das mulheres com deficiência em todas as IES; c) reivindicar a representatividade das mulheres com deficiência em todos os segmentos sociais, políticos, econômicos e ambientais; d) sugerir e participar do processo de construção e fortalecimento de uma rede em prol da acessibilidade e permanência das mulheres com deficiência em todos os campos educacionais e profissionais.

Contudo, construir esse espaço plural é tornar o ensino superior o que verdadeiramente ele precisa ser: um espaço democrático, formador de opiniões autônomas e conscientes, de produção de conhecimento, que deve combater qualquer tipo de discriminação e preconceito, pois só assim quiçar caminharemos para a construção de uma sociedade mais justa e menos desigual. Para que principalmente esses espaços de ensino e aprendizagem, possam fundamentar suas práticas em prol de uma efetivação e garantia de direitos das mulheres com deficiências em seu processo educacional. 
Dadas todas as reflexões apresentadas até aqui, a importância e urgência da temática deixamos as seguintes reflexões para trabalhos futuros com a temática: que mecanismos são indispensáveis para que as universidades públicas se tornem um espaço, de fato, plural de democrático? Quais as redes de apoios necessárias para que as mulheres com deficiências tenham trajetórias escolares menos excludentes e opressoras? Não podemos deixar essas vozes silenciadas e acreditamos que a produção científica se coloca como um instrumento para que elas ecoem e cheguem a diferentes espaços. O desafio maior consiste em garantir que outras pesquisas sejam realizadas nesse sentido, principalmente para que possam trazer outros relatos sobre o acesso e permanência de mulheres no ensino superior.

\section{Referências}

Andrade, F. M. R. (2017). Natureza Amazônica e Educação Ambiental: identidades, saberes docentes e representações sociais. Revista Científica RUNAE, Azogues - Ecuador, 51-70. https://revistas.unae.edu.ec/index.php/runae/article/download/154/121.

Andrade, F. M. R., \& Corrêa, M. S. T. (2020). Pedagogia e mulheres em movimentos: enfrentamentos à violência doméstica. Curitiba: Appris, 2020.

Araújo, R. K. N. (2017). Vilãs ressentidas ou heroínas improváveis? o ethos da mulher com deficiência em telenovelas brasileiras. [Dissertação de Mestrado em Educação Contemporânea, Universidade Federal de Pernambuco]. CA Agreste. https://repositorio.ufpe.br/handle/123456789/29615.

Bardin, L. (1977). Análise de conteúdo. Edições 70.

Brasil. (2001). Ministério da Educação. Parecer CNE/CEB n ${ }^{o}$ 17/2001. http://portal.mec.gov.br/cne/arquivos/pdf/CEB017_2001.pdf.

Brasil. (2008). Ministério da Educação. Política de Educação Especial na Perspectiva da Educação Inclusiva. MEC. http://portal.mec.gov.br/seesp/arquivos/pdf/politica.pdf.

Brasil. (2015). Presidência da República. Lei $n^{o}$ 13.146, de 6 de julho de 2015. Lei Brasileira de Inclusão da Pessoa com Deficiência (Estatuto da Pessoa com Deficiência). http://www.planalto.gov.br/ccivil_03/_ato2015-2018/2015/lei/113146.htm.

Butler, J. (2010). Corpos que pensam: sobre os limites discursivos do sexo. (Louro, G. L., Org.). (Tomaz T.S., Tradução). O corpo Educado: Pedagogias da Sexualidade. Autêntica.

Castro, M. G. (2012). Temas persistentes e enfoques emergentes. Resgatando o conceito de patriarcado em gênero. In Arilha, M.; Caetano; A. J.; Guedes, M.; Marcondes, G. dos S. (org.). Diálogos Transversais em Gênero e Fecundidade: articulações contemporâneas. Campinas: Librum, Associação Brasileira de Estudos Populacionais, $131-146$

Decreto no 3.298 de 20 de dezembro de 1999 (1999, 20 de dezembro). Regulamenta a Lei $n^{o}$ 7.853/1989. Brasília: Presidência da República. http://www. planalto.gov.br/ccivil_03/decreto/d3298. htm.

Decreto $\mathrm{n}^{\mathrm{o}} 5.296$ de 2 de dezembro de 2004 (2004, 2 de dezembro). Regulamenta as Leis $n$. 10.048/2000, que dá prioridade de atendimento às pessoas que especifica, e n. 10.098/2000, que estabelece normas gerais e critérios básicos para a promoção da acessibilidade das pessoas portadoras de deficiência ou com mobilidade reduzida, e dá outras providências. http://www.planalto.gov.br/ccivil_03/_Ato2004-2006/2004/Decreto/D5296.htm.

Decreto $\mathrm{n}^{\mathrm{o}} 5.626$ de 22 de dezembro de 2005 (2005, 22 de dezembro). Regulamenta a Lei $n^{\circ}$ 10.436/2002, que dispõe sobre a Língua Brasileira de Sinais Libras. Recuperado 13 Mai, 2021. http://www.planalto.gov.br/ccivil_03/_ato2004-2006/2005/decreto/d5626.htm

Dicher, M. \& Trevisam, E. (2014). A jornada histórica da pessoa com deficiência: inclusão como exercício do direito à dignidade da pessoa humana. Direitos fundamentais e democracia III [on-line]. CONPEDI/UFPB. Florianópolis, 2014. http://publicadireito.com.br/artigos/?cod=572f88dee7e2502b.

Gil, A. C. (2010). Como elaborar projetos de pesquisa. (5.ed.). Atlas.

Goellner, S. V. (2010). A Educação dos corpos, dos gêneros e das sexualidades e o reconhecimento da diversidade. Cadernos de Formação RBCE, 71-83. http://revista.cbce.org.br/index.php/cadernos/article/view/984

Gugel, M. A. (2008). A pessoa com deficiência e sua relação com a história da humanidade. ANPID. http://www.ampid.org.br/ampid/Artigos/PD_Historia.php.

Louro, G. L. (2010). O corpo Educado: Pedagogias da Sexualidade. (Tomaz T.S., Tradutor). Autêntica.

Ludke, M. \& Andre, M. E. D. A. (2013). Pesquisas em educação: uma abordagem qualitativa. E.P.U.

Mazzota, M. J. S. (1996). Educação Especial no Brasil: História e políticas públicas. Cortez.

Mello, A. G., \& Nuernberg, A. H. (2013). Corpo, Gênero e Sexualidade na Experiência da Deficiência: algumas notas de campo. In: III Seminário Enlaçando Sexualidades: direito, educação, gênero, religião e direitos humanos, Salvador. Anais III Seminário Enlaçando Sexualidades 2013, 1-13. http://conselhos.social.mg.gov.br/conped/images/conferencias/corpo_genero_sexualidade.pdf.

Melo Lopes, F. A. S. (2018). Mulheres com deficiência no ensino superior: tendências a partir de trajetórias no contexto da universidade pública. [Tese de Doutorado em Serviço Social, Universidade Federal de Pernambuco]. Centro de Ciências Sociais e Aplicadas. https://repositorio.ufpe.br/handle/123456789/33463. 
Research, Society and Development, v. 10, n. 7, e26510716670, 2021

(CC BY 4.0) | ISSN 2525-3409 | DOI: http://dx.doi.org/10.33448/rsd-v10i7.16670

Mendes, E. G. (2006). A radicalização do debate sobre inclusão escolar no Brasil. Revista Brasileira de Educação [online]. (11), n. 33, 387-405. https://doi.org/10.1590/S1413-24782006000300002.

Moreira, L.C., Bolsanello, M.A., \& Seger, R.G. (2011). Ingresso e permanência na Universidade: alunos com deficiências em foco. Educar em Revista, (41), 125-143. https://doi.org/10.1590/S0104-40602011000300009.

Pateman, C. (1993). O contrato sexual. (Marta A., Tradução). Paz e Terra.

Rossi, C. M. S. (2020). Educação Inclusiva e Especial. Apostila da Pós-graduação em Docência EAD, (2a ed.), Instituto Federal de Minas Gerais (Campus Arcos) - IFMG. Arcos.

Saffioti, H. (2004). Gênero, patriarcado, violência. Perseu Abramo.

Sánchez, P. A. (2005). A educação inclusiva: um meio de construir escolas para todos os no século XXI. BRASIL, Ministério da Educação. Secretaria da Educação Especial. Revista Inclusão: Revista da Educação Especial, I $\quad(01), \quad 7-18 . \quad$ MEC/SEESP. http://portal.mec.gov.br/seesp/arquivos/pdf/revistainclusao1.pdf.

Sassaki, R. K. (2005). Inclusão: o paradigma do século 21. Revista Inclusão, da Seesp/MEC, I (1), 19-23. https://document.onl/documents/sassaki-rk-inclusaoo-paradigma-do-sec-21.html.

Scott, J. (1989). Gender: a useful category of historical analyses. Gender and the politics of history. Columbia University Press. (Tradução Dabat, C. R.; Ávila, M. B.).

Silva, M. O. E. (2009). Da exclusão à inclusão: concepções e práticas. Revista Lusófona de Educação, 13, (13), 34-43. https://revistas.ulusofona.pt/index.php/rleducacao/article/view/562/459.

UFPE. (2016). Portaria Normativa $N^{o}$ 04, de 16 de fevereiro de 2016. Recife. https://www.ufpe.br/documents/465824/0/PORTARIA+NORM ATIVA+NACE.pdf/2394504c-db74-4f60-9a83-748ad8299432. 